\title{
Improvement of the fraction of human mercaptalbumin on hemodialysis treatment using hydrogen-dissolved hemodialysis fluid: a prospective observational study
}

Kenji Maeda ${ }^{1 *}$, Shigehito Yoshizaki ${ }^{2}$, Toshiro lida ${ }^{1}$, Tomoyoshi Terada ${ }^{3}$, Seiichi Era ${ }^{3}$, Keiichiro Sakashita ${ }^{4}$ and Hajime Arikawa ${ }^{5}$

\begin{abstract}
Background: Oxidative stress (OS) is said to increase in hemodialysis therapy, so that the electrolyzed water-hemodialysis (EW-HD) dissolving hydrogen in hemodialysis fluid has been tried for the reduction of OS. It is reported that the risk of cardiovascular disease events increased if the fraction of reduced albumin (human mercaptalbumin (f(HMA))) was low and that the $\mathrm{f}(\mathrm{HMA})$ rose at the dialyzer outlet on EW-HD. Therefore, we studied whether the $\mathrm{f}(\mathrm{HMA})$ of hemodialysis patients was improved when they received long-term EW-HD treatment.

Methods: We produced hydrogen-dissolved hemodialysis fluid with EW-C81-HD and carried out EW-HD treatment for 12 patients. The serum albumin redox states of pre- and post-HD were measured in the summer of 2014 (EWHD2014) and in the winter of 2015 (EWHD2015) after 6 months by high-performance liquid chromatography using Shodex-Asahipak ES-502N 7C column. For comparison, 38 conventional hemodialysis (C-HD) patients and 24 healthy subjects were selected.

Results: The $\mathrm{f}(\mathrm{HMA})$ of EWHD2015 significantly increased from EWHD2014 on both pre- and post-HD (pre, 51. $32 \pm 5.63 \% \rightarrow 58.03 \pm 7.43 \%$; post, $72.04 \pm 5.73 \% \rightarrow 76.42 \pm 4.67 \%)$. The $f(H M A)$ of C-HD at pre- and post-HD were $51.07 \pm 9.07$ and $70.53 \pm 8.05 \%$, respectively. The $f(H M A)$ of healthy subjects was $79.11 \pm 5.46 \%$. The $\mathrm{f}(\mathrm{HMA})$ of EWHD2014 at pre-HD evidenced no significant difference with that of C-HD at pre-HD, but the $\mathrm{f}(\mathrm{HMA})$ of EWHD2015 at pre-HD was significantly higher than that of C-HD at pre-HD. The f(HMA) of C-HD at post-HD was significantly lower than that of both EWHD2015 at post-HD and healthy subjects, but the $\mathrm{f}(\mathrm{HMA})$ of EWHD2015 at post-HD showed no significant difference with that of healthy subjects.

Conclusions: Our data suggest that the $\mathrm{f}(\mathrm{HMA})$ may be raised with long-term hemodialysis treatment using hydrogen-dissolved hemodialysis fluid.
\end{abstract}

Keywords: Hemodialysis, Hydrogen-dissolved hemodialysis fluid, Electrolyzed water-hemodialysis, Human mercaptalbumin, Human nonmercaptalbumin, Albumin redox, Oxidative stress

* Correspondence: daikoupaper@gmail.com

${ }^{1}$ Daiko Sunadabashi Clinic, Nagoya, Japan

Full list of author information is available at the end of the article 


\section{Background}

The dialysis patient population in Japan was 310,007 at the end of 2012. The characteristics of the dialysis patients include the long dialysis vintage, aging, and increased rate of diabetic nephropathy on primary disease. The patient population surviving over 25 years of dialysis was 12,307 (4.1\%). Their mean age was 66.9 years, and the percentage over 75 years of age was $29.6 \%$. On the primary disease, the percentage of diabetic nephropathy was $37.1 \%$ and that of chronic glomerulonephritis was $33.6 \%$ [1]. The life convalescence of a dialysis patient is far worse than that of the general population [2], and one of the main causes is considered to be oxidative stress (OS) related with hemodialysis therapy $[3,4]$. One of the OS markers was the albumin oxidation-reduction ratio [5]. The reduced form of albumin decreases from a point of chronic kidney disease before the dialysis therapy [6], and that is lower in hemodialysis and peritoneal dialysis patients. The cardiovascular event and death risk are as high as the reduced form of albumin is low $[7,8]$.

In present dialysis therapy, various kinds of treatments are carried out to reduce the risk of mortality and the frequency of complications. The hydrogen molecules remove a hydroxyl radical and reduce the OS [9], so its effects are expected on the hemodialysis therapy.

The electrolyzed water-hemodialysis (EW-HD) dissolving hydrogen in hemodialysis fluid is one of the various kinds of treatments to reduce OS. The EW-HD treatment was first reported by Huang et al. [10]. In Japan, the clinical application of EW-HD was carried out by Nakayama et al. [11]. Its effects such as anemia improvement, blood pressure control, and the reduction of the OS were then reported $[12,13]$.

We began the EW-HD treatment from January 2014 in Daiko Sunadabashi Branch Clinic, too, and began examining clinical effects of EW-HD from July. One previous report showed that EW-HD might improve OS more effectively than conventional HD (C-HD) session. In this report, the authors adapted the redox state of human serum albumin (HSA-redox) as a marker of OS: they found that a fraction of reduced albumin (human mercaptalbumin (f(HMA))) rose at the dialyzer outlet only on EW-HD treatment [14]. However, there is still no long-term study regarding the long-term effect of EW-HD on HSA-redox profile. Therefore, we studied whether the $\mathrm{f}(\mathrm{HMA})$ of $\mathrm{HD}$ patients increased when they received long-term EW-HD treatment. This is why we report here this interesting $\mathrm{f}(\mathrm{HMA})$ increase with long-term EW-HD treatment.

\section{Methods}

Subject

Twelve patients (male/female; 6/6) received EW-HD, 38 (male/female; 24/14) received C-HD, and 24 people were healthy subjects (male/female; 11/13). The age and/or other parameters are shown in Table 1 . No patient who took a drug had a reduction action.

Primary disease, age, and sex were not required for the condition of the subjects, but the patients having cirrhosis or a malignant tumor were excluded.

\section{Production of the hydrogen-dissolved hemodialysis fluid} The reverse osmosis water dissolving hydrogen $(\mathrm{H} 2-\mathrm{RO}$ water) that was produced by the Reverse Osmosis Purified Water Production System for EW-HD; EWC81-HD (Trim Medical Institute Co., Ltd. Sendai, Japan) was used for the product water. The hydrogen-dissolved hemodialysis fluid was produced by the Multiple Patient Dialysis Fluid Supply System; DAB-20NX (NIKKISO Co., Ltd. Tokyo, Japan). The concentrated liquid for hemodialysis fluid was produced by Dialysis Powder Mixing Device; DAD-50 (NIKKISO Co., Ltd. Tokyo, Japan) using $\mathrm{H} 2-\mathrm{RO}$ water and Dialysis Powder; D DRY -2.5S/3.0S (NIKKISO Co., Ltd. Tokyo, Japan). (Fig. 1).

Table 1 Profile of subjects

\begin{tabular}{|c|c|c|c|}
\hline & \multicolumn{3}{|c|}{ Median (min - max) } \\
\hline & EW-HDa & $\mathrm{C}-\mathrm{HD}$ & Healthy subjects \\
\hline Gender (M/F) & $6 / 6$ & $24 / 14$ & $11 / 13$ \\
\hline Age (years old) & $70(57-83)$ & $73(37-89)$ & $39(21-54)$ \\
\hline Primary disease (DM/non-DM) & $6 / 6$ & $14 / 24$ & - \\
\hline Body weight at post-HD (kg) & $48.7(43.7-64.7)$ & $53.3(33.3-87.5)$ & - \\
\hline HD treatment time (hours) & $4.0(3.5-4.0)$ & $4.0(3.0-5.0)$ & - \\
\hline HD vintage (months) & $8(1-150)$ & $22(2-128)$ & - \\
\hline EW-HD vintage (days) & 75 (19-210) & - & - \\
\hline
\end{tabular}

There was no significant difference between EW-HD and C-HD

${ }^{\mathrm{a} A t} 2014$ 


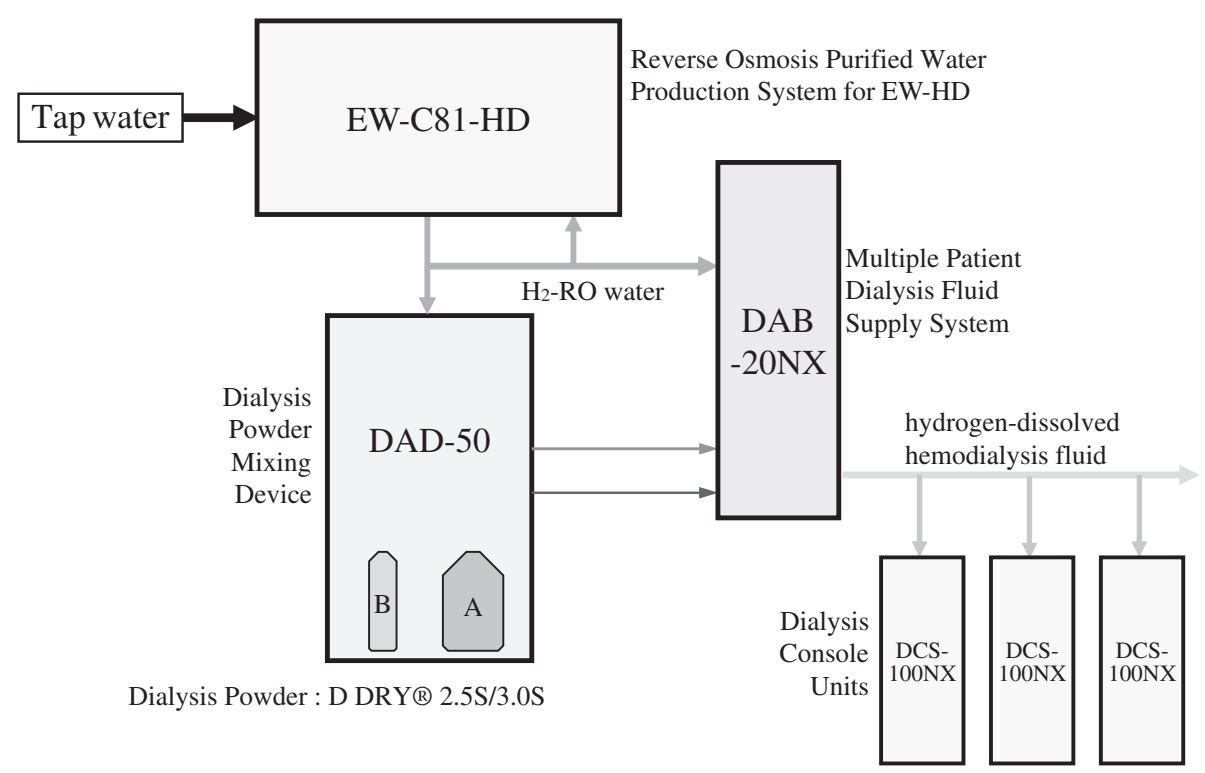

Fig. 1 Schema of production process of hydrogen-dissolved hemodialysis fluid

\section{Dialysis conditions}

The dialysis conditions for the hemodialysis patients are shown in Table 2. All patients did not receive hemodiafiltration treatment. There were no differences in treatment time, hemodialysis frequency, dialyzer type and membrane material, membrane area, quantity of blood flow $\left(\mathrm{Q}_{\mathrm{B}}\right)$, or dialysis dose between EW-HD and C-HD. The quantity of hemodialysis fluid flow $\left(\mathrm{Q}_{\mathrm{D}}\right)$ was $500 \mathrm{~mL} / \mathrm{min}$ in all patients. The dialysis powder of CHD was Kindaly 4E (Fuso Pharmaceutical Industries, Ltd., Osaka, Japan). The compositions of hemodialysis fluid in C-HD are almost the same as those in EW-HD.

Table 2 Dialysis condition

\begin{tabular}{|c|c|c|c|}
\hline & EW-HD $(n=12)$ EWHD2014 $\rightarrow$ EWHD015 & $\mathrm{C}-\mathrm{HD}(n=38)$ & Notes \\
\hline Treatment mode & Hemodialysis & Hemodialysis & \\
\hline Treatment time (hour/session) & $3.92 \pm 0.19 \rightarrow 3.96 \pm 0.14$ & $3.95 \pm 0.48$ & Mean \pm SD ns \\
\hline Hemodialysis frequency & 3 times/week & 3 times/week & \\
\hline Dialyzer type/membrane material & V/PS: 6; IV/CTA: $6 \rightarrow$ V/PS: 7; IV/CTA: 5 & V/PS: 14; IV/PS: 8, CTA: 16 & Polysulfone (PS), cellulose triacetate (CTA) \\
\hline Dialyzer membrane area $\left(\mathrm{m}^{2}\right)$ & $1.5(1.3-2.1) \rightarrow 1.7(1.5-2.1)$ & $1.8(1.3-2.5)$ & Median (min-max) ns \\
\hline $\mathrm{Q}_{\mathrm{B}}(\mathrm{mL} / \mathrm{min})$ & $200(180-230) \rightarrow 200(200-230)$ & $200(150-250)$ & Median (min-max) ns \\
\hline $\mathrm{Q}_{\mathrm{D}}(\mathrm{mL} / \mathrm{min})$ & 500 & 500 & \\
\hline Dialysis dose: KTN for urea & $1.45 \pm 0.15 \rightarrow 1.55 \pm 0.19$ & $1.45 \pm 0.24$ & Mean \pm SD ns \\
\hline Body weight pre-HD (kg) & $52.9 \pm 6.4 \rightarrow 54.3 \pm 6.3$ & $56.6 \pm 11.5$ & Mean \pm SD ns \\
\hline post-HD (kg) & $50.7 \pm 6.4 \rightarrow 51.9 \pm 6.5$ & $54.1 \pm 10.9$ & Mean \pm SD ns \\
\hline Dialysis powder & $D D R Y^{\circ}-2.5 S / 3.0 S$ & Kindaly 4E & \\
\hline \multicolumn{4}{|l|}{ Compositions of hemodialysis fluid } \\
\hline $\mathrm{Na}^{+}(\mathrm{mEq} / \mathrm{L})$ & 140.0 & 140.0 & \\
\hline $\mathrm{K}^{+}(\mathrm{mEq} / \mathrm{L})$ & 2.0 & 2.0 & \\
\hline $\mathrm{Ca}^{2+}(\mathrm{mEq} / \mathrm{L})$ & 2.75 & 2.75 & \\
\hline $\mathrm{Mg}^{2+}(\mathrm{mEq} / \mathrm{L})$ & 1.0 & 1.0 & \\
\hline $\mathrm{Cl}^{-}(\mathrm{mEq} / \mathrm{L})$ & 112.25 & 112.25 & \\
\hline $\mathrm{HCO}_{3}{ }^{-}(\mathrm{mEq} / \mathrm{L})$ & 25.0 & 27.5 & \\
\hline $\mathrm{CH}_{3} \mathrm{COO}^{-}(\mathrm{mEq} / \mathrm{L})$ & 10.0 & 8.0 & \\
\hline $\mathrm{C}_{6} \mathrm{H}_{12} \mathrm{O}_{6}(\mathrm{mg} / \mathrm{dL})$ & 100.0 & 125.0 & \\
\hline
\end{tabular}




\section{Measurements}

HMA and HNA (human nonmercaptalbumin) were measured by high-performance liquid chromatography (HPLC) as reported in the previous paper [14]. Briefly, the HPLC system consisted of an AS-8010 auto-sampler (Tosoh, Tokyo, Japan; $2 \mu \mathrm{L}$ injection volume) and a CCPM doubleplunger pump (Tosoh) in conjunction with a CO-8011 system controller (Tosoh). Chromatographs were obtained using a UV6000LP photodiode alley detector (detection area, 200-600 nm with $1 \mathrm{~nm}$ step; Thermo Electron, Waltham, MA, USA). A Shodex-Asahipak ES-502 N 7C column $(10 \times 0.76 \mathrm{~cm}$ I.D., DEAE form for ion-exchange HPLC; Showa Denko, Tokyo, Japan; column temperature, $35 \pm 0.5{ }^{\circ} \mathrm{C}$ ) was used in this study.

The $\mathrm{f}(\mathrm{HMA})$ was calculated with the following equation, $\mathrm{f}(\mathrm{HMA})=[\mathrm{HMA} /(\mathrm{HMA}+\mathrm{HNA})] \times 100(\%)$.

The serum samples were collected from EW-HD patients in August/September 2014 (EWHD2014) and February/March 2015 (EWHD2015), from C-HD patients in August 2014 February 2015, from healthy subjects in September/October 2014. The samples were frozen at $-80{ }^{\circ} \mathrm{C}$ until measurement. The sampling from the patients was carried out at the pre- and post-HD at the beginning of the week.

The hydrogen concentration in hemodialysis fluid was measured by Portable Dissolved Hydrogen Meter; DH35A (DKK-TOA CO., LTD. Tokyo, Japan).

\section{Data analysis}

The data were shown in mean \pm standard deviation. The Stat View 5.0 (Hulinks Inc., Tokyo, Japan) software was used for statistical tests. The differences of EWHD2014 and EWHD2015 were compared by paired $t$ test. The multiple comparison procedure was carried out for statistical analysis among EW-HD, C-HD, and healthy subjects. We assumed less than $5 \%$ of levels of significance as a statistical significance standard.

\section{Results}

The $\mathrm{f}(\mathrm{HMA})$ of pre- and post-HD were $51.32 \pm 5.63$ and $72.04 \pm 5.73 \%$ at EWHD2014, respectively. The f(HMA) of pre- and post-HD were $58.03 \pm 7.43$ and $76.42 \pm$ $4.67 \%$ at EWHD2015, respectively. The f(HMA) of preand post-HD on $\mathrm{C}$-HD were $51.07 \pm 9.07$ and $70.53 \pm$
$8.05 \%$, respectively. The $\mathrm{f}(\mathrm{HMA})$ of healthy subjects was $79.11 \pm 5.46 \%$ (Table 3 ).

Table 4 shows the blood data of the patients at the time of sampling.

On the EW-HD, the $\mathrm{f}(\mathrm{HMA})$ at 2015 significantly increased from 2014 on both pre- and post-HD (Fig. 2).

On comparison with $\mathrm{C}-\mathrm{HD}$ at pre-HD, the $\mathrm{f}(\mathrm{HMA})$ of EWHD2014 showed no significant difference with that of C-HD, but the $\mathrm{f}(\mathrm{HMA})$ of EWHD2015 was significantly higher than that of C-HD (Fig. 3).

In the relationship between the $\mathrm{HD}$ vintage and $\mathrm{f}(\mathrm{HMA})$ at pre-HD, there were no correlation both in CHD and EWHD2014(Fig. 4).

On comparison among EWHD2015, C-HD and healthy subjects, the $\mathrm{f}(\mathrm{HMA})$ of $\mathrm{C}-\mathrm{HD}$ at post-HD were significantly lower than those of EWHD2015 at post-HD and healthy subjects, but the f(HMA) of EWHD2015 at post-HD showed no significant difference with that of healthy subjects (Fig. 5).

The concentration of hydrogen in hemodialysis fluid was measured several times after the beginning of EWHD, and ranged 47 196 ppb (Table 5).

\section{Discussion}

Albumin is the main antioxidant in plasma [5], and we paid attention to HSA-redox and examined it. As for the human albumin, the free thiol of 34-cysteine is reduced albumin (HMA), and the disulfide bond of 34-cysteine is oxidative albumin (HNA). HMA plays an important role in the antioxidant mechanism in extracellular fluid [5]. The $\mathrm{f}(\mathrm{HMA})$ in serum decreases with aging, but that in cerebrospinal fluid does not change [15]. The control mechanism of albumin redox has not fully been examined, but Matsuyama et al. reported that human astrocytes and aortic endothelial cells are actively converted to HMA from HNA [15]. The f(HMA) decreases with a renal dysfunction [6], so the kidney may do some kind of participation in albumin redox. In the hemodialysis patients who have almost no renal function, it is thought that the albumin redox adjustment function is lowered during non-hemodialysis treatment. In the albumin redox of hemodialysis patients, the $\mathrm{f}$ (HMA) increased to nearly normal levels post-HD when hemodialysis treatment was performed, but decreased afterward, and was

Table 3 Albumin redox of patients and healthy subjects

\begin{tabular}{|c|c|c|c|c|c|c|c|}
\hline & & & & & \multicolumn{3}{|c|}{$(\%)$ mean \pm SD } \\
\hline & \multicolumn{2}{|c|}{ EWHD2014 $(n=12)$} & \multicolumn{2}{|c|}{ EWHD2015 $(n=12)$} & \multicolumn{2}{|l|}{$\mathrm{C}-\mathrm{HD}(n=38)$} & \multirow{2}{*}{$\begin{array}{l}\text { Healthy } \\
\text { subjects } \\
(n=24)\end{array}$} \\
\hline & Pre-HD & Post-HD & Pre-HD & Post-HD & Pre-HD & Post-HD & \\
\hline $\mathrm{f}(\mathrm{HMA})$ & $51.32 \pm 5.63$ & $72.04 \pm 5.73$ & $58.03 \pm 7.43$ & $76.42 \pm 4.67$ & $51.07 \pm 9.07$ & $70.53 \pm 8.05$ & $79.11 \pm 5.46$ \\
\hline $\mathrm{f}(\mathrm{HNA})$ & $48.68 \pm 5.63$ & $27.96 \pm 5.73$ & $41.97 \pm 7.43$ & $23.58 \pm 4.67$ & $48.93 \pm 9.07$ & $29.47 \pm 8.05$ & $20.89 \pm 5.46$ \\
\hline
\end{tabular}

$f(H M A)$ fraction of human mercaptalbumin, $f(H N A)$ fraction of human nonmercaptalbumin $f(H N A)=100-f(H M A)$ 
Table 4 Data of blood and physical situation in patients

\begin{tabular}{|c|c|c|c|}
\hline & \multicolumn{3}{|l|}{ Mean \pm SD } \\
\hline & EWHD2014 $(n=12)$ & EWHD2015 $(n=12)$ & $\mathrm{C}-\mathrm{HD}(n=38)$ \\
\hline BUN (mg/dL) & $56.05 \pm 11.25$ & $56.53 \pm 13.39$ & $62.27 \pm 12.73$ \\
\hline $\mathrm{Cr}(\mathrm{mg} / \mathrm{dL})$ & $8.98 \pm 2.32$ & $9.20 \pm 1.78$ & $10.05 \pm 2.4$ \\
\hline UA (mg/dL) & $6.99 \pm 1.21$ & $6.98 \pm 1.12$ & $6.84 \pm 1.29$ \\
\hline $\mathrm{Hb}(\mathrm{g} / \mathrm{dL})$ & $10.91 \pm 1.033$ & $10.98 \pm 0.73$ & $11.26 \pm 1.20$ \\
\hline WBC $(/ \mu \mathrm{L})$ & $6121 \pm 2493$ & $6605 \pm 2039$ & $5827 \pm 2046$ \\
\hline $\mathrm{CRP}(\mathrm{mg} / \mathrm{dL})$ & $0.552 \pm 1.015^{\mathrm{a}}$ & $0.542 \pm 0.747$ & $0.234 \pm 0.492^{b}$ \\
\hline Alb (g/dL) & $3.49 \pm 0.20$ & $3.65 \pm 0.24^{*}$ & $3.53 \pm 0.23$ \\
\hline GOT (U/L) & $13.3 \pm 2.4$ & $14.1 \pm 2.3$ & $31.4 \pm 105.0$ \\
\hline GPT (U/L) & $9.2 \pm 2.8$ & $10.3 \pm 5.0$ & $25.5 \pm 88.1$ \\
\hline T-Cho (mg/dL) & $154 \pm 39$ & $165 \pm 47$ & $146 \pm 24$ \\
\hline nPCR (g/kg/day) & $0.81 \pm 0.13$ & $0.83 \pm 0.16$ & $0.87 \pm 0.15$ \\
\hline \%CGR (\%) & $93.2 \pm 32$ & $98.2 \pm 27$ & $99.0 \pm 25.4$ \\
\hline $\mathrm{BMI}\left(\mathrm{kg} / \mathrm{m}^{2}\right)$ & $20.1 \pm 2.9$ & $20.6 \pm 3.2^{*}$ & $21.5 \pm 3.3$ \\
\hline GNRI (-) & $89.2 \pm 5.0$ & $92.1 \pm 6.3^{* *}$ & $91.3 \pm 5.1$ \\
\hline
\end{tabular}

${ }^{*} p<0.05$ (paired $t$-test vs EWHD2014); ${ }^{* *} p<0.01$ (paired $t$-test vs EWHD2014) Other data were no significant difference

${ }^{a} n=10$

${ }^{b} n=13$

lower than for healthy persons before hemodialysis treatment [16]. The data of our study indicated similar results but the significant difference with healthy subjects was not only the $\mathrm{f}(\mathrm{HMA})$ of post-HD in EWHD2015, but the low numerical value.

As to previous study regarding the relationship between HSA-redox and EW-HD, Terawaki et al. [14] reported the beneficial effect of single EW-HD session on
HSA-redox [14]. Our present study, however, deals with the long-term (201 392 days) effect of EW-HD treatment on HSA-redox profile. In our study, data were collected at only one point in C-HD; however, it was thought that there was little possibility of the change by HD vintage (Fig. 4). It is suggested that the $\mathrm{f}(\mathrm{HMA})$ of hemodialysis patients improves with long-term EW-HD treatment.

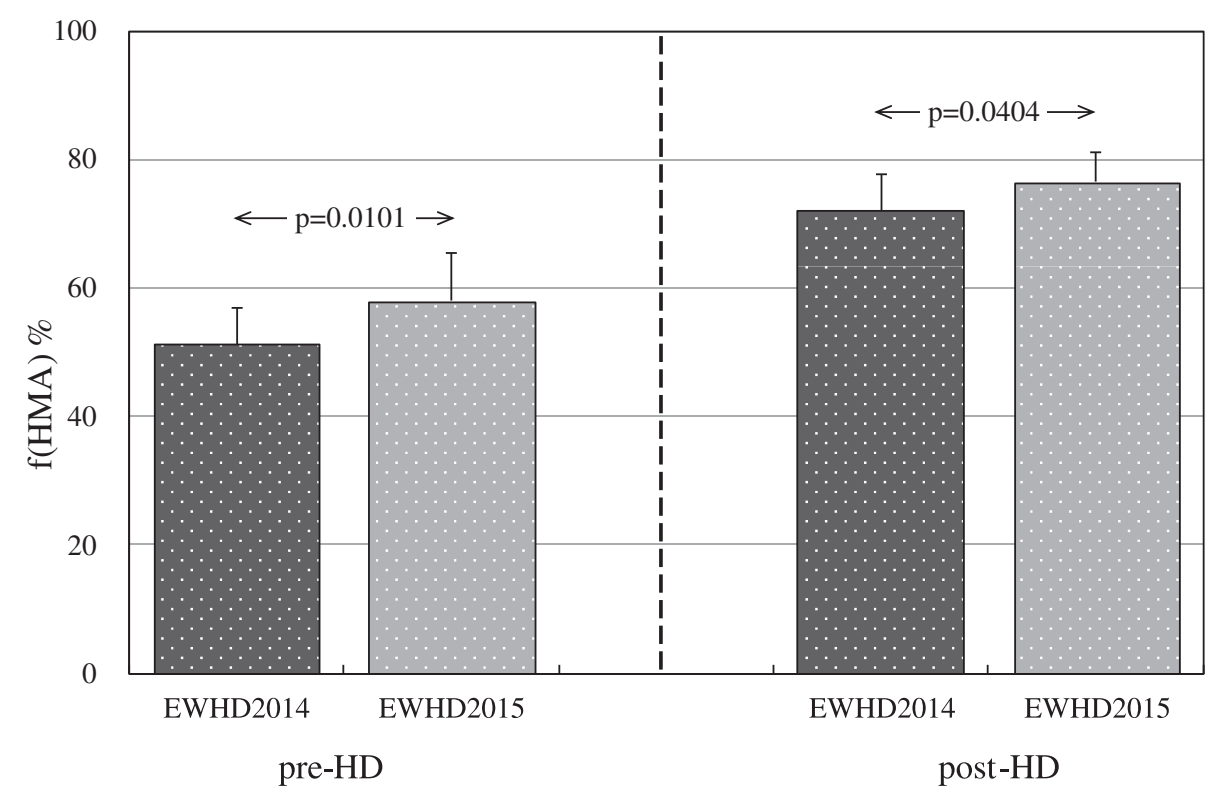

Fig. 2 Comparison of the $\mathrm{f}(\mathrm{HMA})$ on EWHD2014 vs EWHD2015. $n=12$ : both at pre- and post-HD 


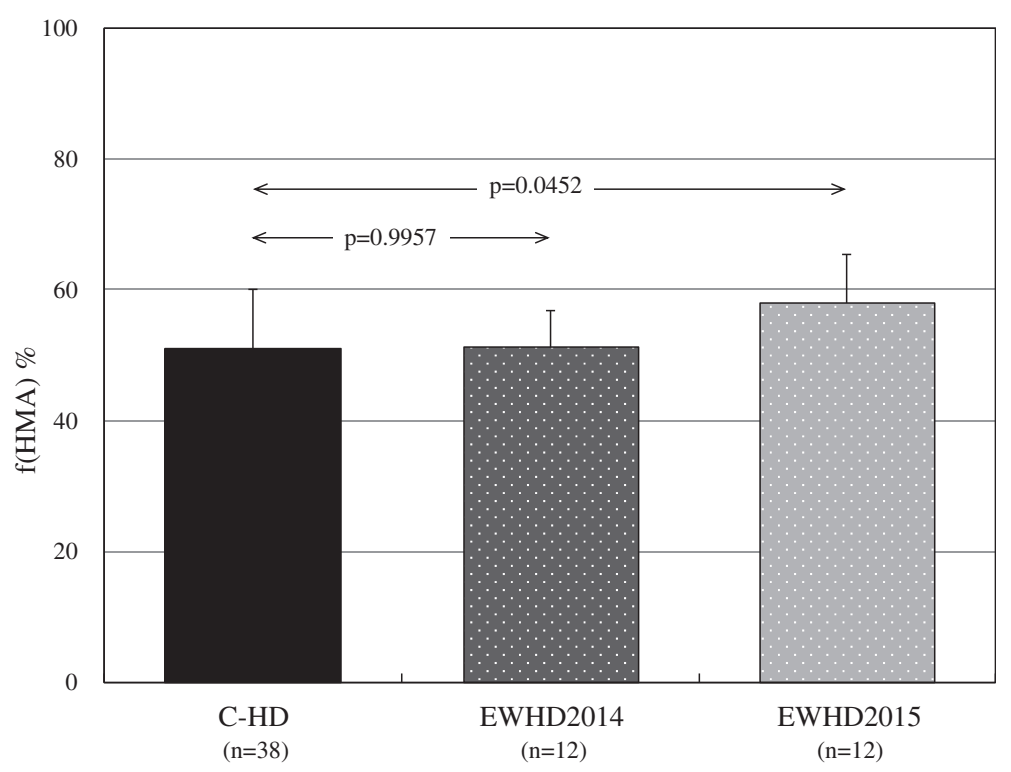

Fig. 3 Comparison of the $f(H M A)$ in pre-HD

Terawaki et al. reported that the risk of cardiovascular disease (CVD) events and mortality were very high at pre-HD $\mathrm{f}(\mathrm{HMA})<40 \%$ or post-HD $\mathrm{f}(\mathrm{HMA})<60 \%$; in particular, the odds ratios of CVD incidence and mortality in the post-HD $\mathrm{f}(\mathrm{HMA})<60 \%$ were 20.6 and 25.6 times by those in the post-HD f(HMA) $\geq 60 \%$, respectively [7]. In our study, the C-HD treatment patients who were $\mathrm{f}(\mathrm{HMA})<40 \%$ at pre-HD were $4(10.5 \%)$ and, those of the $\mathrm{f}(\mathrm{HMA})<60 \%$ at post-HD were $3(7.9 \%)$, but no EW-HD treatment patient corresponded to those conditions.
The pre-HD albumin levels at EWHD2015 were significantly increased compared with those at EWHD2014, to 3.65 from $3.49 \mathrm{~g} / \mathrm{dL}$, likewise BMI and GNRI were significantly increased (Table 4). If all the rising values were HMA, the f(HMA) increased only to 53.45 from $51.32 \%$. And, the dialyzer and/or the reduction of body weight that influence on albumin leakage during hemodialysis were no different between EWHD2014 and EWHD2015 (Table 2). Therefore, EW-HD is more likely to contribute to the rise of HMA. Long-term EW-HD treatment presumably resulted in the rise of HMA by the

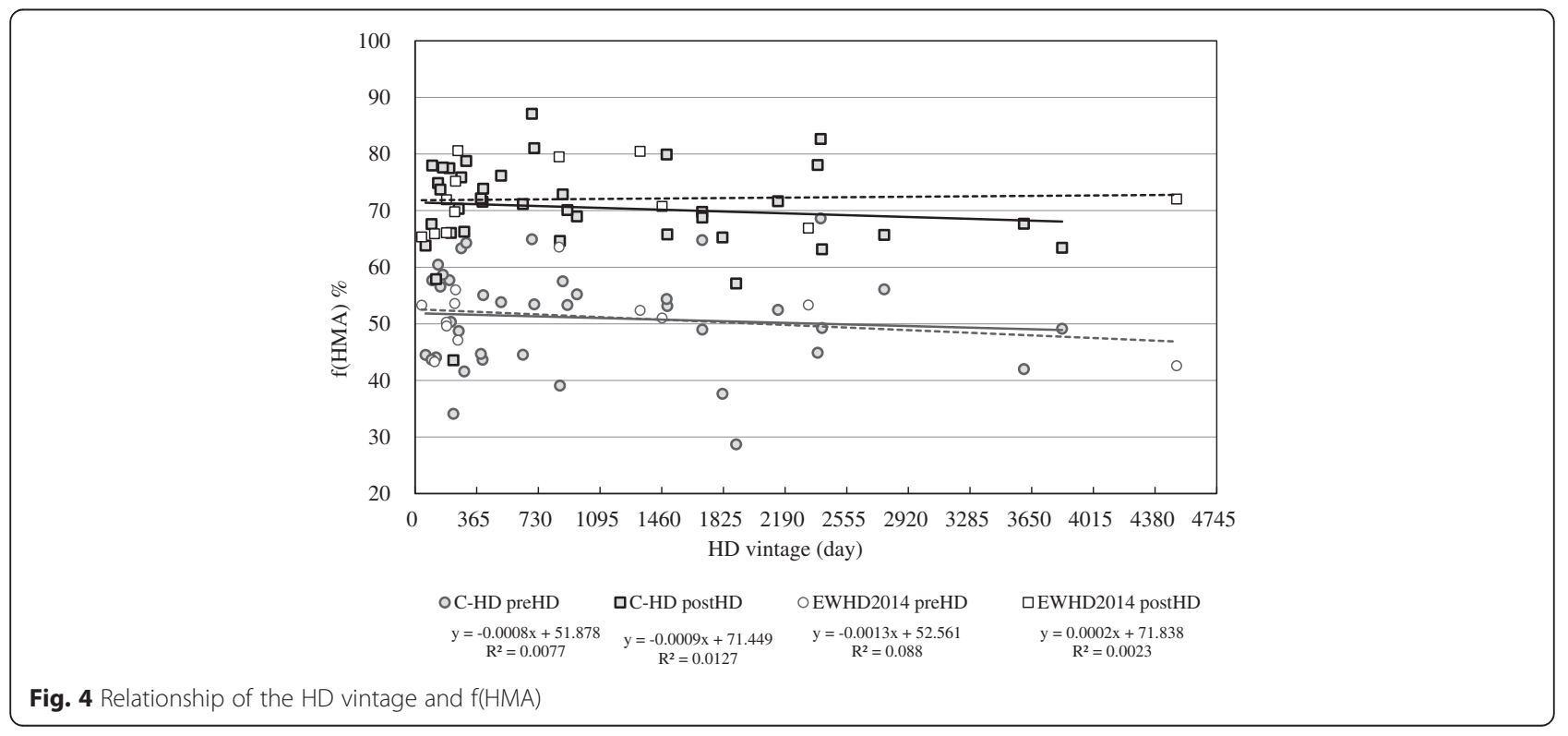




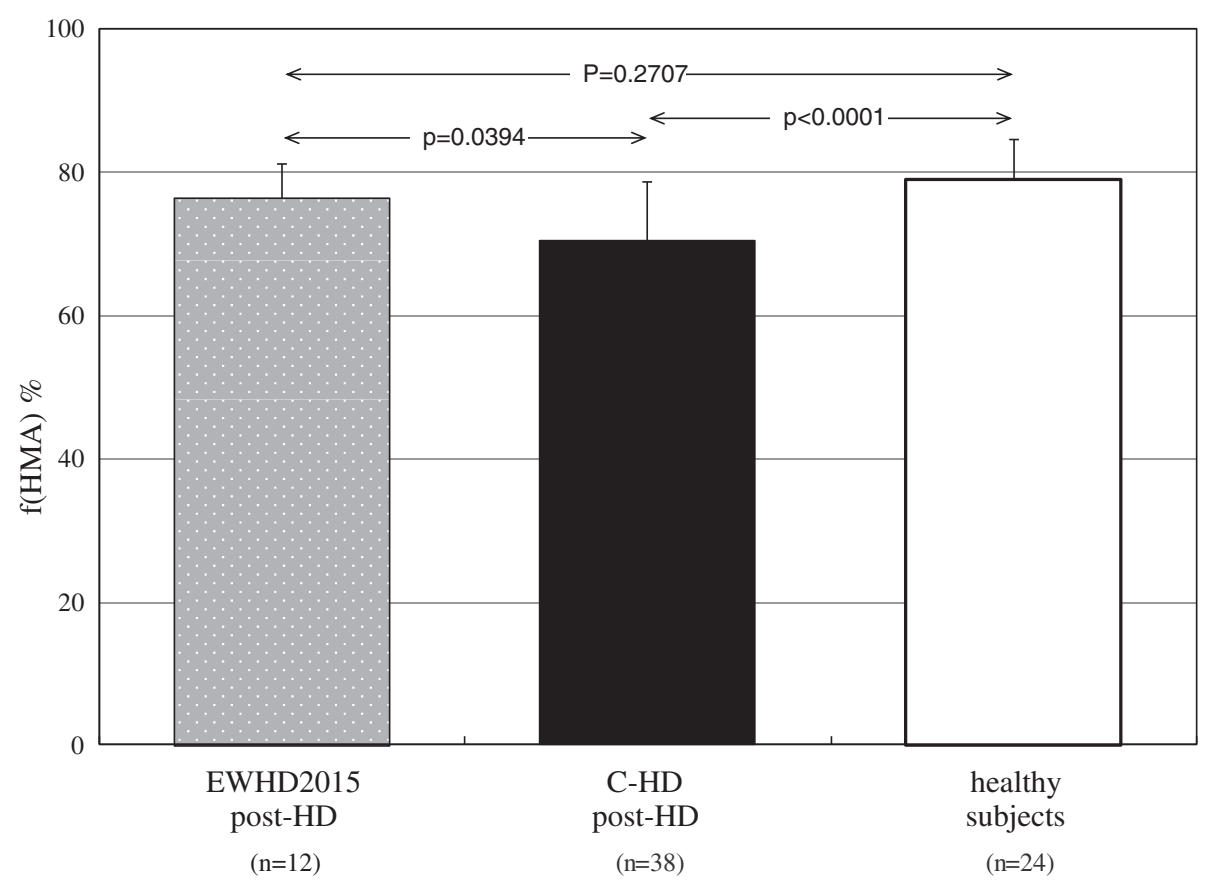

Fig. 5 Comparison of the $\mathrm{f}(\mathrm{HMA})$ in post-HD and healthy subjects

accumulation of albumin reduction effect in the dialyzer [14] and/or the improvement of blood vessel wall function [15]. In a comparison of EWHD2014 and EW2015, the preHD $\mathrm{f}(\mathrm{HMA})$ values increased and the difference in the $\mathrm{f}(\mathrm{HMA})$ value between pre- and post-HD decreased. It is thought that the latter contribution is greater, and the possible effectiveness of the prevention of CVD events by long-term EW-HD treatment was suggested.

Nakayama et al. reported that EW-HD ameliorated inflammatory reactions and offered a novel therapeutic option for control of uremia [17]. Huang et al. reported that 1-year treatment improved T cell damage [18]. MIA syndrome has been proposed as one of the disease states influencing the vital prognosis of hemodialysis patients. MIA syndrome is a syndrome that occurs in relation to malnutrition, inflammation and atherosclerosis, of which inflammation is considered to take a central role [19]. The inflammatory reaction and the oxidation LDL generation may be decrease directly or indirectly by the reduction action of hydrogen, so we expect that longer-

Table 5 Hydrogen concentration of the EW-HD fluid

\begin{tabular}{lll}
\hline Measurement day & Minimum & Maximum \\
\hline $2014 / 04 / 17$ & 47 & 107 \\
$2014 / 06 / 18$ & 62 & 122 \\
$2014 / 08 / 04$ & 50 & 111 \\
$2014 / 11 / 10$ & 67 & 161 \\
$2015 / 02 / 02$ & 84 & 196 \\
\hline
\end{tabular}

Concentration unit is ppb term EW-HD treatment will show clinical usefulness such as a lower frequency of complications and/or improvement of vital prognosis.

\section{Study limitations}

There are several limitations in this study. The number of EW-HD subjects is small, and the observation period in EW-HD treatment is not sufficient to detect any clinical outcome. It will therefore be necessary to evaluate albumin redox in more patients with longer-term EWHD treatment.

\section{Conclusions}

Our data suggest that the $\mathrm{f}(\mathrm{HMA})$ may be raised with long-term hemodialysis treatment using hydrogendissolved hemodialysis fluid.

\section{Acknowledgements}

This study was supported by Kiyomi Inada, Ritsuko Ando, Izumi Tamai, Chie Shirakawa, and Syunsuke Nakashima of the Daiko Sunadabashi Clinic and Yukie Hirabayashi, Yayoi Kondo, and Hirochika Kato of the Daiko Sunadabashi Branch Clinic.

\section{Authors' contributions}

KM and KS conceived of the study and participated in its design and coordination. HY and TI participated in the design of the study. KM, HY, and TI carried out the selections of patients. $\Pi$ and SE carried out the measurements of the samples. HA, KS, and ES performed the statistical analysis. KS and SE helped to draft the manuscript. KM organized the study project and drafted the final manuscript. All authors read and approved the final manuscript.

\section{Authors' information}

KM is the director of the Daiko Sunadabashi Clinic, the representative director of the Japanese Academy of Home Care Physicians, the chairman of 
the Public Interest Incorporated Foundation Aichi Kidney Foundation, and the professor emeritus of Nagoya University. HY is the director of the Daiko Sunadabashi Branch Clinic. TI is the physician of the Daiko Sunadabashi Clinic. SE is the professor of the Gifu University Graduate School of Medicine. $\Pi$ is the lecturer of the Gifu University Graduate School of Medicine. KS is the head of the Laboratory of Dialysis Medical Care and Technology. HA is the associate professor of the Chubu Gakuin College.

\section{Competing interests}

The authors declare that they have no competing interests.

\section{Ethics approval and consent to participate}

Our study received approval from the ethic examination of the "Ethical Review Board, Nagoya Medical Association" on June 28, 2014 (accept No. 2014-3-6). We obtained written informed consent from the subjects and registered them as study subjects.

\section{Author details}

'Daiko Sunadabashi Clinic, Nagoya, Japan. 'Daiko Sunadabashi Branch Clinic, Nagoya, Japan. ${ }^{3}$ Department of Physiology and Biophysics, Graduate School of Medicine, Gifu University, Gifu, Japan. ${ }^{4}$ Laboratory of Dialysis Medical Care and Technology, Nagoya, Japan. ${ }^{5}$ Department of Early Childhood Education, Chubu Gakuin College, Seki, Gifu, Japan.

Received: 17 November 2015 Accepted: 10 June 2016

Published online: 05 September 2016

\section{References}

1. Nakai S, Hanafusa N, Masakane I, Taniguchi M, Hamano T, Shoji T, et al. An overview of regular dialysis treatment in Japan (as of 31 December 2012). Ther Apher Dial. 2014;18:535-602.

2. Nakai S, Masakane I, Akiba T, Iseki K, Watanabe Y, Itami N, et al. Overview of regular dialysis treatment in Japan (as of 31 December 2005). Ther Apher Dial. 2007;11:411-41.

3. Locatelli F, Canaud B, Eckardt KU, Stenvinkel P, Wanner C, Zoccali C. Oxidative stress in end-stage renal disease: an emerging threat to patient outcome. Nephrol Dial Transplant. 2003;18:1272-80.

4. Morena M, Delbosc S, Dupuy AM, Canaud B, Cristol JP. Overproduction of reactive oxygen species in end-stage renal disease patients: a potential component of hemodialysis-associated inflammation. Hemodial Int. 2005;9:37-46.

5. Anraku M, Chuang VT, Maruyama T, Otagiri M. Redox properties of serum albumin. Biochim Biophys Acta. 1830;2013:5465-72.

6. Terawaki H, Yoshimura K, Hasegawa T, Nakayama M, Hosoya T, Era S, et al. Oxidative stress is enhanced in correlation with renal dysfunction: examination with the redox state of albumin. Kidney Int. 2004;66:1988-93.

7. Terawaki H, Takada Y, Era S, Funakoshi Y, Nakayama K, Nakayama M, et al. The redox state of albumin and serious cardiovascular incidence in hemodialysis patients. Ther Apher Dial. 2010;14:465-71.

8. Terawaki H, Matsuyama Y, Matsuo N, Terada T, Era S, Hosoya T, et al. A lower level of reduced albumin induces serious cardiovascular incidence among peritoneal dialysis patients. Clin Exp Nephrol. 2012;16:629-35.

9. Ohsawa I, Ishikawa M, Takahashi K, Watanabe M, Nishimaki K, Yamagata K, et al. Hydrogen acts as a therapeutic antioxidant by selectively reducing cytotoxic oxygen radicals. Nat Med. 2007;13:688-94.

10. Huang KC, Yang CC, Lee KT, Chiang-Ting Chien CT. Reduced hemodialysisinduced oxidative stress in end-stage renal disease patients by electrolyzed reduced water. Kidney Int. 2003;64:704-14.

11. Nakayama M, Kabayama S, Terawaki H, Nakayama K, Kato K, Sato T, et al. Less-oxidative hemodialysis solution rendered by cathode-side application of electrolyzed water. Hemodial Int. 2007;11:322-7.

12. Huang KC, Yang CC, Hsu SP, Lee KT, Liu HW, Morisawa S, et al. Electrolyzedreduced water reduced hemodialysis-induced erythrocyte impairment in end-stage renal disease patients. Kidney Int. 2006;70:391-8.

13. Nakayama M, Kabayama S, Nakano H, Zhu WJ, Terawaki H, Nakayama K, et al. Biological effects of electrolyzed water in hemodialysis. Nephron Clin Pract. 2009;112:C9-c15.

14. Terawaki H, Zhu WJ, Matsuyama Y, Terada T, Takahashi Y, Sakurai K, et al. Effect of a hydrogen $\left(\mathrm{H}_{2}\right)$-enriched solution on the albumin redox of hemodialysis patients. Hemodial Int. 2014;18:459-66.
15. Matsuyama $Y$, Hayashi T, Terawaki H, Negawa T, Terada T, Okano Y, et al. Human astrocytes and aortic endothelial cells actively convert the oxidized form of albumin to the reduced form: reduced albumin might participate in redox regulation of nerve and blood vessel systems. J Physiol Sci. 2009;59:207-15.

16. Soejima A, Matsuzawa N, Hayashi T, Kimura T, Ootsuka R, Fukuoka K, et al. Alteration of redox state of human serum albumin before and after hemodialysis. Blood Purif. 2004;22:525-9.

17. Nakayama M, Nakano $H$, Hamada $H$, Itami $N$, Nakazawa $R$, Ito S. A novel bioactive haemodialysis system using dissolved dihydrogen $\left(\mathrm{H}_{2}\right)$ produced by water electrolysis: a clinical trial. Nephrol Dial Transplant. 2010;25:3026-33.

18. Huang KC, Hsu SP, Yang CC, Ou-Yang P, Lee KT, Morisawa S, et al. Electrolysed-reduced water dialysate improves T-cell damage in end-stage renal disease patients with chronic haemodialysis. Nephrol Dial Transplant. 2010;5:2730-7.

19. Stenvinkel $P$, Heimbürger $O$, Lindholm B, Kaysen GA, Bergström J. Are there two types of malnutrition in chronic renal failure? Evidence for relationships between malnutrition, inflammation and atherosclerosis (MIA syndrome). Nephrol Dial Transplant. 2000;15:953-60.

\section{Submit your next manuscript to BioMed Central and we will help you at every step:}

- We accept pre-submission inquiries

- Our selector tool helps you to find the most relevant journal

- We provide round the clock customer support

- Convenient online submission

- Thorough peer review

- Inclusion in PubMed and all major indexing services

- Maximum visibility for your research

Submit your manuscript at www.biomedcentral.com/submit
BioMed Central 